\title{
The relationship between dispositional empathy, psychological distress, and posttraumatic stress responses among Japanese uniformed disaster workers: a cross-sectional study
}

Masanori Nagamine ${ }^{1 *}$ D, Jun Shigemura ${ }^{2}$, Toshimichi Fujiwara ${ }^{3}$, Fumiko Waki ${ }^{3}$, Masaaki Tanichi ${ }^{2}$, Taku Saito $^{2}$, Hiroyuki Toda ${ }^{2}$, Aihide Yoshino ${ }^{2}$ and Kunio Shimizu ${ }^{1}$

\begin{abstract}
Background: Disaster workers suffer from psychological distress not only through the direct experience of traumatic situations but also through the indirect process of aiding disaster victims. This distress, called secondary traumatic stress, is linked to dispositional empathy, which is the tendency for individuals to imagine and experience the feelings and experiences of others. However, the association between secondary traumatic stress and dispositional empathy remains understudied.

Methods: To examine the relationship between dispositional empathy and mental health among disaster workers, we collected data from 227 Japan Ground Self-Defense Force personnel who engaged in international disaster relief activities in the Philippines following Typhoon Yolanda in 2013. The Impact of Event Scale-Revised and the Kessler Psychological Distress Scale were used to evaluate posttraumatic stress responses (PTSR) and general psychological distress (GPD), respectively. Dispositional empathy was evaluated through the Interpersonal Reactivity Index, which consists of four subscales: Perspective Taking, Fantasy, Empathic Concern, and Personal Distress. Hierarchial linear regression analyses were performed to identify the variables related to PTSR and GPD.

Results: High PTSR was significantly associated with high Fantasy (identification tendency, $\beta=0.21, p<.01$ ), high Personal Distress (the self-oriented emotional disposition of empathy, $\beta=0.18, p<.05$ ), and no experience of disaster relief activities $(\beta=0.15, p<.05)$. High GPD was associated with high Personal Distress $(\beta=0.28, p<.001)$, marital status (married, $\beta=0.22, p<.01)$, being female $(\beta=0.18, p<.01)$, medical unit $(\beta=0.18, p<.05)$, and no experience of disaster relief activities $(\beta=0.13, p<.05)$.

Conclusions: Among Japanese uniformed disaster workers, high PTSR was associated with two subtypes of dispositional empathy: the self-oriented emotional disposition of empathy and high identification tendency, whereas high GPD was associated with high identification tendency. Educational interventions that aim to mitigate these tendencies might be able to relieve the psychological distress of disaster workers.
\end{abstract}

Keywords: Disaster workers, Empathy, Interpersonal reactivity index, Identification, Secondary traumatic stress, Posttraumatic stress response, Psychological distress

\footnotetext{
* Correspondence: nagaminemasanori@gmail.com

${ }^{1}$ Division of Behavioral Science, National Defense Medical College Research

Institute, 3-2 Namiki, Tokorozawa, Saitama 359-8513, Japan

Full list of author information is available at the end of the article
}

(c) The Author(s). 2018 Open Access This article is distributed under the terms of the Creative Commons Attribution 4.0 International License (http://creativecommons.org/licenses/by/4.0/), which permits unrestricted use, distribution, and

reproduction in any medium, provided you give appropriate credit to the original author(s) and the source, provide a link to the Creative Commons license, and indicate if changes were made. The Creative Commons Public Domain Dedication waiver (http://creativecommons.org/publicdomain/zero/1.0/) applies to the data made available in this article, unless otherwise stated. 


\section{Background}

On November 8, 2013, Typhoon Yolanda struck the Philippines and caused large-scale damage: 6300 individuals were killed, 28,688 were injured, and 1062 were missing [1]. The Japanese government responded to a humanitarian assistance request from the Filipino government and sent Japan Self-Defense Forces' personnel to the affected area. Disaster relief activities consisted of medical assistance, epidemic prevention, and transport of relief supplies [2], which continued until December 18, 2013.

Disasters result in mental health distress not only among survivors but also among disaster workers [3, 4]. These individuals have the burden of rescuing lives in disaster-stricken sites fraught with life-threatening danger. In addition to such direct traumatic stresses, disaster workers can also experience indirect psychological effects of aiding disaster victims, which is defined as secondary traumatic stress [5]. These psychological effects can result in various reactions, including depression and anxiety disorder, in addition to stress-related disorders, such as acute and post-traumatic stress disorder [6]. According to a recent meta-analysis, the pooled prevalence of posttraumatic stress disorder among rescue workers was $10 \%$ [7], indicating the magnitude of their work-related traumatic experience on worker's mental health. Countermeasures for work-related traumatic stress are crucial for disaster workers to prevent adverse mental health outcomes. Coping strategies to mitigate such impacts include sufficient training prior to missions [8-10], awareness of and pride in one's duties [11, 12], and humor $[8,13,14]$. Minimization of excessive empathy and identification with victims is also recommended to prevent traumatic stress [8, 15-17], which is supported by two empirical studies $[15,17]$.

Empathy is a multi-dimensional concept with emotional and cognitive components [18]. Davis defined empathy as the "reactions of one individual to the observed experiences of another" and developed the Interpersonal Reactivity Index (IRI), which is a multi-dimensional scale of empathic traits [19]. The IRI consists of four subscales: Perspective Taking (PT; the tendency to spontaneously adopt the psychological point of view of others), Fantasy (FS; the respondents' tendencies to transpose themselves imaginatively into the feelings and actions of fictitious characters in books, movies, and plays), Empathic Concern (EC; "other-oriented" feelings of sympathy and concern for unfortunate others), and Personal Distress (PD; "self-oriented" feelings of personal anxiety and unease in tense interpersonal settings). Although the construct of self-oriented negative feeling (e.g., PD) is not included in the narrowly defined empathy [20], IRI provides multifaceted information on aspects of dispositional empathy and thus, is one of the most widely used measures to evaluate empathy [21].
As to the relationships between empathy and secondary traumatic stress, Figley reported that individuals who have a great capacity to feel and express empathy tend to be more vulnerable to the traumatic stress in his studies of healthcare workers [22]. Klimecki and Singer suggest that the consequence of empathy take on two paths; one is an "other-oriented," or compassion that results in prosocial motivation or positive feelings, and the other is a "self-oriented" personal distress that results in withdrawal or the experience of negative feelings [23]. In disaster workers, the latter path might explain their development of posttraumatic stress responses. However, to the best of our knowledge, the relationship between the empathy and secondary traumatic stress has yet to be fully investigated. To expand the theoretical and professional knowledge regarding secondary traumatic stress in the field of traumatic stress, we examined the relationships between dispositional empathy (measured with the IRI) and mental health (posttraumatic stress and psychological distress) among Japan Ground Self-Defense Force (JGSDF) personnel who were deployed on a humanitarian mission in response to the disaster of Typhoon Yolanda in 2013.

\section{Methods}

\section{Participants and procedure}

This survey was conducted as part of the mandatory occupational health management of all JGSDF personnel who were engaged in the humanitarian mission after Typhoon Yolanda $(N=283)$. The self-report survey was administered immediately after they returned home using registered (i.e., non-anonymous) forms. Of all the personnel, only 227 participated and provided written consent (response rate: $80.2 \%$ ).

\section{Psychological evaluation}

We assessed two outcome measures-posttraumatic stress responses (PTSR) and general psychological distress (GPD) - using the Japanese versions of the Impact of Events Scale-Revised (IES-R) [24] and the Kessler Psychological Distress Scale (K10) [25], respectively. The IES-R is a 22-item self-administered questionnaire (score range: $0-88$ ) that is used to evaluate three domains of PTSR-intrusion, avoidance, and hyperarousal-following a traumatic event [26]. The $\mathrm{K} 10$ is a 10 -item self-administered questionnaire (score range: 10-50) that was developed by Kessler [27] and is widely used as a tool for evaluating GPD. The originally reported Cronbach's alpha for internal consistency was 0.91 for the K10 [28] and 0.92 to 0.95 for the IES-R [24]. In this study, Cronbach's alphas of 0.91 for the IES-R and 0.89 for the K10 were obtained.

Dispositional empathy was evaluated using the IRI [19]. The IRI is a 28-item self-report measure answered on a 5-point Likert scale. It consists of four subscales (PT, FS, EC, and PD), and each subscale contains seven 
different items (score ranges from 0 to 28). A previous paper reported Cronbach's alphas of 0.65 for PT, 0.76 for FS, 0.77 for EC, and 0.76 for PD [29]. In this study we obtained Cronbach's alphas of 0.63 for PT, 0.62 for FS, 0.57 for EC, and 0.65 for PD.

In addition to these psychological measures, the following information was collected based on the previous report by Berger and colleagues [7]: age, sex, marital status, rank, unit (e.g., medical, airlift, others), previous disaster relief experience, exposure to human bodies during relief efforts, and previous psychiatric treatment history.

\section{Statistical analyses}

First, Pearson correlation analyses were performed to explore the correlation between dispositional empathy and PTSR or GPD. Second, analysis of variance was used for the univariate analyses of each personal attribute. Finally, hierarchical linear regression analyses were conducted to investigate factors related to PTSR and GPD. In Step 1, personal attributes including age, sex, marital status, previous deployment experience, psychiatric treatment history were entered as covariates. In Step 2, work-related factors such as rank, unit (e.g., medical or airlift), and exposure to bodies were added as covariates. In Step 3, dispositional empathy evaluated using the four subscales of the IRI (PT, FS, EC, and PD) that were entered as predictor variables.

We used a significance level of $p<.05$. IBM SPSS Statistics for Windows version 22 was used for the statistical tests [30].

\section{Results}

\section{Personal attributes and the results of the univariate analyses}

The average age of the participants was $35.59 \pm 7.99$ years $($ mean $\pm S D$ ). As Table 1 demonstrates, those with no previous disaster relief experience scored significantly higher on both PTSR and GPD than those with previous disaster relief experience. In addition, women, officers, and individuals assigned to medical units showed significantly higher scores on GPD than did men, those who were Enlisted/Private, and individuals assigned to "others" units, respectively.

\section{Psychological measures and correlation analyses}

Table 2 presents the summary statistics for the psychological measures and the results of the Pearson correlation analyses between the measures. IES-R was significantly correlated with two IRI subscales: FS $(r=.28, p<.001)$ and PD $(r=.25, p<.001)$. K10 showed a significant correlation with three IRI subscales: PD $(r=.35, p<.001)$, FS $(r=.23$, $p<.001)$, and EC $(r=.18, p<.01)$. There were significant correlations between the IRI subscales, except for PT and PD.
Table 1 Personal attributes and the results of the univariate analyses

\begin{tabular}{|c|c|c|c|c|c|c|}
\hline & \multirow[b]{2}{*}{$N$} & \multirow[b]{2}{*}{$\%$} & \multicolumn{2}{|l|}{ PTSR } & \multicolumn{2}{|l|}{ GPD } \\
\hline & & & Mean & $S D$ & Mean & SD \\
\hline \multicolumn{7}{|l|}{ Sex } \\
\hline Male & 214 & 94.3 & 4.6 & 6.7 & 12.7 & 3.6 \\
\hline Female & 13 & 5.7 & 7.7 & 6.3 & $17.2^{* * *}$ & 8.0 \\
\hline \multicolumn{7}{|l|}{ Marital status } \\
\hline Single & 81 & 35.7 & 4.0 & 5.9 & 12.4 & 3.5 \\
\hline Married & 146 & 64.3 & 5.2 & 7.1 & 13.2 & 4.4 \\
\hline \multicolumn{7}{|l|}{ Rank } \\
\hline Enlisted/Private & 143 & 63.0 & 4.3 & 5.8 & 12.3 & 3.1 \\
\hline Officer & 84 & 37.0 & 5.6 & 7.9 & $13.9^{* *}$ & 5.3 \\
\hline \multicolumn{7}{|l|}{ Unit } \\
\hline Medical & 53 & 23.3 & 5.9 & 7.1 & $14.1^{\mathrm{a}}$ & 5.3 \\
\hline Airlift & 97 & 42.7 & 4.8 & 7.5 & 13.0 & 3.8 \\
\hline Others & 77 & 33.9 & 3.9 & 5.3 & 12.0 & 3.2 \\
\hline \multicolumn{7}{|c|}{ Disaster relief experience } \\
\hline Yes & 193 & 85.0 & 4.3 & 6.1 & 12.6 & 3.9 \\
\hline No & 34 & 15.0 & $7.5^{*}$ & 8.9 & $14.9^{* *}$ & 4.6 \\
\hline \multicolumn{7}{|l|}{ Exposure to bodies } \\
\hline No & 216 & 95.2 & 4.8 & 6.8 & 12.9 & 4.1 \\
\hline Yes & 11 & 4.8 & 3.5 & 4.4 & 13.5 & 4.6 \\
\hline \multicolumn{7}{|c|}{ Psychiatric treatment history } \\
\hline No & 219 & 98.2 & 4.8 & 6.7 & 12.9 & 4.1 \\
\hline Yes & 4 & 1.8 & 8.5 & 7.2 & 11.0 & 2.0 \\
\hline
\end{tabular}

$N=227$. PTSR Posttraumatic stress response evaluated by the Impact of Event Scale-Revised, GPD General psychological distress evaluated by the Kessler Psychological Distress Scale, SD standard deviation

${ }^{a}$ Individuals who were assigned to medical units showed significantly higher scores than others ( $p<.05$, multiple comparisons with the Bonferroni correction) ${ }^{*} p<.05,{ }^{* *} p<.01,{ }^{* * *} p<.001$

\section{Hierarchical linear regression analyses}

The results of the hierarchical linear regression analyses for high PTSR and GPD are shown in Table 3. It is reported that any variance inflation factor (VIF) exceeds 10 and tolerance value lower than 0.10 indicates a potential problem of multicollinearity [31]. In this study, variance inflation factor (VIF) ranged from 1.007 to 1.621 and tolerance ranged from 0.617 to 0.993 throughout the hierarchical linear regression analyses, no multicollinearity was observed. Regarding the correlates of PTSR, significant associations were observed for two IRI subscales: FS $(\beta=0.21, \mathrm{SE}=0.11, p<.01)$ and $\mathrm{PD}(\beta=0.18, \mathrm{SE}=0.13$, $p<.05)$. Having no experience of disaster relief was also significantly associated with high PTSR $(\beta=0.15$, $\mathrm{SE}=1.3, p<.05)$. For the correlates of high GPD status, significant relations were shown for PD $(\beta=0.28$, $\mathrm{SE}=0.07, p<.001$ ), marital status (married, $\beta=0.22$, $\mathrm{SE}=0.61, p<.01)$, being female $(\beta=0.18, \mathrm{SE}=1.15, p<.01)$, medical unit $(\beta=0.18, \mathrm{SE}=0.68, p<.05)$, and no disaster relief experience $(\beta=0.13, \mathrm{SE}=0.73, p<.05)$. Therefore, the 
Table 2 Results of the psychological measures and Pearson correlation analyses

\begin{tabular}{|c|c|c|c|c|c|c|c|c|c|c|c|}
\hline & IES-R & K10 & IRI_PT & IRI_FS & IRI_EC & $\mid \mathrm{RI} \_P D$ & Mean & SD & Median & Range & Cronbach's alpha \\
\hline IES-R & - & $.59^{* * *}$ & .07 & $.28^{* * *}$ & .05 & $.25^{* * *}$ & 4.77 & 6.70 & 2 & $0-40$ & 0.91 \\
\hline K10 & & - & .13 & $.23^{* * *}$ & $.18^{* *}$ & $.35^{* * *}$ & 12.91 & 4.09 & 11 & 10-39 & 0.89 \\
\hline$|\mathrm{R}| \_\mathrm{PT}$ & & & - & $.14^{*}$ & $.43^{* * *}$ & .04 & 15.90 & 4.09 & 16 & $5-28$ & 0.63 \\
\hline$|R| \_F S$ & & & & - & $.22^{* *}$ & $.39^{* * *}$ & 9.67 & 4.28 & 9 & $0-22$ & 0.62 \\
\hline $\mid \mathrm{RI} E \mathrm{EC}$ & & & & & - & $.28^{* * *}$ & 16.89 & 3.59 & 17 & $8-28$ & 0.57 \\
\hline$|R| \_P D$ & & & & & & - & 10.31 & 3.88 & 10 & $2-22$ & 0.65 \\
\hline
\end{tabular}

Note. $N=227$. IES-R Impact of Event Scale-Revised, K10 Kessler Psychological Distress Scale, IRI Interpersonal Reactivity Index, PT Perspective Taking, FS Fantasy, EC Empathic Concern, $P D$ Personal Distress, SD standard deviation

${ }^{*} p<.05,{ }^{* *} p<.01,{ }^{* * *} p<.001$

two IRI subscales, FS and PD, showed the largest standardized coefficient $\beta$ in the multiple linear regression models for PTSR and GPD, respectively.

\section{Discussion}

We examined the associations between dispositional empathy and the mental health status (PTSR and GPD) of
JGSDF personnel who were engaged in the international disaster relief activity after Typhoon Yolanda in 2013. High PTSR was significantly related to both high FS and PD. High GPD was significantly related to high PD. To our knowledge, this is the first paper to report a link between psychological distress or posttraumatic stress and dispositional empathy among disaster workers using quantitative empathy measures.

Table 3 Results of the hierarchical multiple linear regression analysis

\begin{tabular}{|c|c|c|c|c|c|c|}
\hline & \multicolumn{3}{|c|}{ PTSR Hierarchial Models } & \multicolumn{3}{|c|}{ GPD Hierarchial Models } \\
\hline & \multicolumn{3}{|c|}{ Standardized Coefficient $\beta$} & \multicolumn{3}{|c|}{ Standardized Coefficient $\beta$} \\
\hline & Step 1 & Step 2 & Step 3 & Step 1 & Step 2 & Step 3 \\
\hline \multicolumn{7}{|l|}{ Personal Attributes } \\
\hline Age & 0.02 & 0.02 & 0.02 & -0.05 & -0.05 & -0.04 \\
\hline $\operatorname{Sex}^{\mathrm{a}}$ & 0.11 & 0.11 & 0.07 & $0.26^{* * *}$ & $0.23^{* *}$ & $0.18^{* *}$ \\
\hline Marital status ${ }^{\mathrm{b}}$ & 0.11 & 0.12 & 0.13 & $0.19^{* *}$ & $0.18^{*}$ & $0.22^{* *}$ \\
\hline Disaster relief experience ${ }^{c}$ & $-0.18^{* *}$ & $-0.17^{*}$ & $-0.15^{*}$ & $-0.19^{* *}$ & $-0.17^{*}$ & $-0.13^{*}$ \\
\hline Psychiatric treatment history ${ }^{c}$ & 0.09 & 0.09 & 0.1 & -0.05 & -0.05 & -0.06 \\
\hline \multicolumn{7}{|l|}{ Work-related factors } \\
\hline $\operatorname{Rank}^{d}$ & & 0.03 & 0.01 & & 0.09 & 0.04 \\
\hline Medical unit ${ }^{c}$ & & 0.09 & 0.1 & & $0.18^{*}$ & $0.18^{*}$ \\
\hline Airlift unit ${ }^{c}$ & & 0.10 & 0.06 & & $0.16^{*}$ & 0.12 \\
\hline Exposure to bodies ${ }^{c}$ & & -0.06 & -0.03 & & 0.03 & 0.06 \\
\hline \multicolumn{7}{|l|}{ Dispositional Empathy } \\
\hline$|R| \_P T$ & & & 0.05 & & & 0.04 \\
\hline IRI_FS & & & $0.21^{* *}$ & & & 0.08 \\
\hline IRI_EC & & & -0.11 & & & 0.03 \\
\hline IRI_PD & & & $0.18^{*}$ & & & $0.28^{* * *}$ \\
\hline \multicolumn{7}{|l|}{ Statistics } \\
\hline$R^{2}$ & 0.057 & 0.071 & 0.164 & 0.13 & 0.166 & 0.271 \\
\hline$\Delta R^{2}$ & & 0.014 & 0.093 & & 0.036 & 0.106 \\
\hline $\mathrm{F}$ & $2.635^{*}$ & 1.815 & $3.150^{* * *}$ & $6.475^{* * *}$ & $4.696^{* * *}$ & $5.984^{* * *}$ \\
\hline
\end{tabular}

$N=227$. PTSR Posttraumatic stress response evaluated by the Impact of Events Scale-Revised, GPD General psychological distress evaluated by the Kessler Psychological Distress Scale, IRI Interpersonal Reactivity Index, PT Perspective Taking, FS Fantasy, EC Empathic Concern, PD Personal Distress

${ }^{a}$ Dummy variable was created $($ male $=0$, female $=1)$. ${ }^{b}$ Dummy variable was created $($ single $=0$, married $=1)$. ${ }^{c}$ Dummy variables were created $(n o=0$, yes $=1$ ).

${ }^{\mathrm{d}}$ Dummy variables were created (enlisted/private $=0$, officer $=1$ )

${ }^{*} p<.05,{ }^{* *} p<.01,{ }^{* * *} p<.001$ 
PD reflects emotional dispositional empathy and represents "self-oriented" feelings of personal anxiety and unease in tense interpersonal settings. Previous research that targeted clinical physicians reported that PD was closely related to secondary traumatic stress [32]. Cognitive neuroscience studies have outlined control mechanisms that regulate whether someone's empathic reactions are self- or other-oriented, indicating the importance of being aware of the distinction between experiences of the self and others [33, 34]. Our study suggests that individuals with high PD-who have a poor ability to distinguish between self- and other-oriented empathic reactions-are prone to suffering from psychological distress when faced with persons experiencing adversity.

FS, which is the tendency to transpose oneself imaginatively into the feelings and actions of fictitious characters, was also extracted as a significant factor related to high PTSR in this study. Ursano and colleagues have shown the importance of "identification with disaster victims" as a mechanism through which relief workers experience secondary trauma [17]. Cetin and colleagues also reported results that support this finding [15] and warned against excessive identification with disaster victims. Considering the conceptual similarity between FS, which is a type of dispositional empathy, and "identification with disaster victims," our results also support these previous findings.

Previous disaster relief-related literature suggests the importance of maintaining professional distance and avoiding excessive empathy and identification with victims $[8,15,17,35]$. A similar trend has been observed in the field of clinical medicine; "detached concern"-a purely cognitive understanding of patients' emotions, while establishing emotional distance to maintain objectivity and limit exposure to negative emotions-has been traditionally recommended for physicians [36]. Given that those with high FS or PD are prone to suffering from psychological distress when faced with distressed individuals, it is likely that maintaining professional or emotional distance, such as "detached concern," is especially helpful for such emergency relief workers in order to minimize their psychological distress. However, this does not necessarily suggest that a complete absence of empathy is appropriate. Empathy is multifaceted; "other-oriented" empathy provide individuals with a variety of positive effects such as compassion satisfaction [37] and positive clinical outcomes [38]. One study targeted at physicians reported that compassion satisfaction was strongly associated with EC and PT, while compassion fatigue was more closely related to PD [32]. Therefore, an educational intervention that could reinforce other-oriented empathic reactions while inhibiting self-oriented empathic reactions might be effective for mitigating the psychological distress of emergency relief workers. It will be crucial to examine the effectiveness of such educational interventions through in-depth follow-up studies. These programs may specifically target workers with high PD or FS in order to prevent their posttraumatic mental health difficulties.

In this study, those with no disaster relief experience were identified as being at risk for both high PTSR and GPD, and women, married individuals, and medical unit were identified as being at risk for high GPD. Previous studies that focused on body handlers also reported that women and inexperienced workers had higher levels of distress than men and experienced workers [39]. Our results are consistent with this previous report. As for marital status, the previous literature has reported that unmarried individuals are more prone to suffer from psychological distress than those who are married [40]. Although our study demonstrated the opposite result, we theorize that being married could be not only protective but also risk factor depending on the marital relationship or family situation. For example, for the married personnel who have not built a good marital relationship, the existence of spouse could work as a concern rather than a social support when they are suddenly assigned for disaster relief work. Such background might induce inconsistent outcomes. Since medical staff were more likely to suffer from direct or indirect traumatic stress in such a major disaster, it was reasonable that being a member of medical unit was identified as the risk factor for high GPD.

\section{Limitations}

Our findings should be interpreted within the context of some limitations. First, our study participants were limited to JGSDF personnel and they did not include other defense services; therefore, our results do not represent all JGSDF personnel engaged in disaster relief activities in the Philippines. Second, this study employed a registered (non-anonymous) questionnaire, which has been reported to cause participants to conceal their symptoms, as compared to an anonymous questionnaire [41]. Furthermore, the Japanese sociocultural background strongly stigmatizes the expression of emotional suffering [42]. Thus, there is a strong possibility that participants' psychological effects were underreported in this study. Third, our cross-sectional study design limits the causal association between the dependent and the independent variables. Finally, this study did not examine other factors that might confound our findings (e.g., pre-deployment mental health status, personal characteristics for coping with stress, previous traumatic experiences, numbers of years of disaster relief experience, compassion satisfaction, and major life event experience). Further studies that include such information are needed to more rigorously identify the psychological effects of these factors for disaster workers. 


\section{Conclusions}

Despite some limitations, we demonstrated that PD and FS, which are subscales of the IRI, are related to psychological distress among disaster workers. Situations that increase the risk of secondary trauma are not limited to disaster relief activities but also include humanitarian aid, such as medical and welfare activities. More precise and better understanding of the relationship between dispositional empathy and psychological distress is needed to design better educational interventions to protect the mental health of people who engage in such activities.

\section{Abbreviations}

EC: Empathic Concern; FS: Fantasy; GPD: General psychological distress; IESR: Impact of Events Scale-Revised; IRI: Interpersonal Reactivity Index; JGSDF: Japan Ground Self-Defense Force; K10: Kessler Psychological Distress Scale; PD: Personal Distress; PT: Perspective Taking; PTSR: Posttraumatic stress response

\section{Acknowledgements}

We wish to thank all the participants and medical staff of the JGSDF who supported our research. The authors would also like to thank Dr. Yumi Suzuki of the International College of Arts and Sciences, Fukuoka Women's University, Fukuoka, Japan, for use of the Japanese version of the IRI. The views expressed in this article are those of the authors and do not reflect the position or policy of the National Defense Medical College or the Japan Ministry of Defense.

\section{Funding}

This work was supported by the Japanese Society for the Promotion of Science KAKENHI Grant number 26461779

\section{Availability of data and materials}

The data supporting the findings are available upon request. Please contact the corresponding author of this paper, Masanori Nagamine

(nagaminemasanori@gmail.com), for data availability.

\section{Authors' contributions}

MN conceived and designed the study, and developed it in discussion with JS, MT, TS, HT, AY, and KS. MN, TF, and FW were involved in the acquisition and analysis of the data, and all authors participated in the interpretation of the data. MN wrote the first draft of the article and all authors contributed to critically revising the paper. Finally, all authors read and approved the final manuscript.

\section{Ethics approval and consent to participate}

This study was conducted with the approval of the Ethics Committee of the National Defense Medical College (approval no. 2109). Written consent was received from all the participants.

\section{Consent for publication}

Not applicable.

\section{Competing interests}

The authors declare that they have no competing interests.

\section{Publisher's Note}

Springer Nature remains neutral with regard to jurisdictional claims in published maps and institutional affiliations.

\section{Author details}

'Division of Behavioral Science, National Defense Medical College Research Institute, 3-2 Namiki, Tokorozawa, Saitama 359-8513, Japan. ²Department of Psychiatry, School of Medicine, National Defense Medical College, 3-2 Namiki, Tokorozawa, Saitama, Japan. ${ }^{3}$ Japan Ground Self-Defense Force Medical School, 1-2-24, Ikejiri, Setagaya-ku, Tokyo, Japan.
Received: 1 May 2018 Accepted: 27 September 2018

Published online: 11 October 2018

\section{References}

1. National Disaster Risk Reduction and Management Council. Final report re: effects of typhoon "Yolanda" (Haiyan). In: NDRRMC update; 2013. http:// ndrrmc.gov.ph/attachments/article/1329/FINAL_REPORT re Effects_of Typhoon_YOLANDA_(HAIYAN)_06-09NOV2013.pdf. Accessed 24 Apr 2018.

2. Cabinet Office of Japan. International contributions of Japan self-defense forces. In: We are Tomodachi; 2014. http://www.japan.go.jp/tomodachi/ 2014/spring-summer2014/international_contributions_of_apan.html. Accessed 24 Apr 2018.

3. Norris FH, Friedman MJ, Watson PJ, Byrne CM, Diaz E, Kaniasty K. 60,000 disaster victims speak: part I. an empirical review of the empirical literature, 1981-2001. Psychiatry. 2002;65:207-39.

4. Perrin MA, DiGrande L, Wheeler K, Thorpe L, Farfel M, Brackbill R. Differences in PTSD prevalence and associated risk factors among world trade center disaster rescue and recovery workers. Am J Psychiatry. 2007;164:1385-94.

5. Figley CR. Compassion fatigue as secondary traumatic stress disorder. In: Figley $C R$, editor. Compassion fatigue: coping with secondary traumatic stress disorder in those who treat the traumatized. New York: Routledge; 1995. p. 1-20.

6. Benedek DM, Fullerton C, Ursano RJ. First responders: mental health consequences of natural and human-made disasters for public health and public safety workers. Annu Rev Public Health. 2007;28:55-68.

7. Berger W, Coutinho ES, Figueira I, Marques-Portella C, Luz MP, Neylan TC, et al. Rescuers at risk: a systematic review and meta-regression analysis of the worldwide current prevalence and correlates of PTSD in rescue workers. Soc Psychiatry Psychiatr Epidemiol. 2012;47:1001-11. https://doi.org/10.1007/ s00127-011-0408-2.

8. Fullerton CS, McCarroll JE, Ursano RJ, Wright KM. Psychological responses of rescue workers: fire fighters and trauma. Am J Orthop. 1992;62:371-8.

9. Guo YJ, Chen CH, Lu ML, Tan HK, Lee HW, Wang TN. Posttraumatic stress disorder among professional and non-professional rescuers involved in an earthquake in Taiwan. Psychiatry Res. 2004;127:35-41. https://doi.org/10. 1016/j.psychres.2004.03.009.

10. Marmar CR, Weiss DS, Metzler TJ, Ronfeldt HM, Foreman C. Stress responses of emergency services personnel to the Loma Prieta earthquake interstate 880 freeway collapse and control traumatic incidents. J Trauma Stress. 1996; 9:63-85.

11. Leffler CT, Dembert ML. Posttraumatic stress symptoms among U.S. navy divers recovering TWA flight 800. J Nerv Ment Dis. 1998;186:574-7.

12. Ursano RJ, McCarroll JE. Exposure to traumatic death: the nature of the stressor. In: Ursano RJ, McCaughey BG, Fullerton CS, editors. Individual and community responses to trauma and disaster: the structure of human chaos. Cambridge: Cambridge University Press; 1994. p. 46-71.

13. Alexander DA, Wells A. Reactions of police officers to body-handling after a major disaster. A before-and-after comparison. Br J Psychiatry. 1991;159:547-55.

14. Jones DR. Secondary disaster victims: the emotional effects of recovering and identifying human remains. Am J Psychiatry. 1985;142:303-7.

15. Cetin M, Kose S, Ebrinc S, Yigit S, Elhai JD, Basoglu C. Identification and posttraumatic stress disorder symptoms in rescue workers in the Marmara, Turkey, earthquake. J Trauma Stress. 2005;18:485-9. https://doi.org/10.1002/ jts.20056.

16. Regehr C, Goldberg G, Hughes J. Exposure to human tragedy, empathy, and trauma in ambulance paramedics. Am J Orthop. 2002:72:505-13.

17. Ursano RJ, Fullerton CS, Vance K, Kao TC. Posttraumatic stress disorder and identification in disaster workers. Am J Psychiatry. 1999:156:353-9. https:// doi.org/10.1176/ajp.156.3.353.

18. Decety J, Svetlova M. Putting together phylogenetic and ontogenetic perspectives on empathy. Dev Cogn Neurosci. 2012;2:1-24. https://doi.org/ 10.1016/j.den.2011.05.003.

19. Davis MH. Measuring individual differences in empathy: evidence for a multidimensional approach. J Pers Soc Psychol. 1983;44:113-26. https://doi. org/10.1037/0022-3514.44.1.113.

20. Batson CD, Fultz J, Schoenrade PA. Distress and empathy: two qualitatively distinct vicarious emotions with different motivational consequences. J Pers. 1987;55:19-39.

21. Stepien KA, Baernstein A. Educating for empathy. A review. J Gen Intern Med. 2006;21:524-30. 
22. Figley CR. Compassion fatigue: Psychotherapists' chronic lack of self care. J Clin Psychol. 2002;58:1433-41. https://doi.org/10.1002/jclp.10090.

23. Klimecki O, Singer T. Empathic distress fatigue rather than compassion fatigue? Integrating findings from empathy research in psychology and social neuroscience. In: Oakley B, Knafo A, Madhavan G, Wilson D, editors. Pathological altruism. New York: Oxford University press; 2012. p. 368-83.

24. Asukai N, Kato H, Kawamura N, Kim Y, Yamamoto K, Kishimoto J, et al. Reliability and validity of the Japanese-language version of the impact of event scale-revised (IES-R-J): four studies of different traumatic events. J Nerv Ment Dis. 2002;190:175-82.

25. Furukawa TA, Kawakami N, Saitoh M, Ono Y, Nakane Y, Nakamura Y, et al. The performance of the Japanese version of the K6 and K10 in the world mental health survey Japan. Int J Methods Psychiatr Res. 2008;17:152-8. https://doi.org/10.1002/mpr.257.

26. Weiss DS, Marmar CR. The impact of event scale-revised. In: Wilson JP Keane TM, editors. Assessing psychological trauma and PTSD. New York: The Guilford Press; 1997. p. 339-411.

27. Kessler RC, Andrews G, Colpe LJ, Hiripi E, Mroczek DK, Normand SL, et al. Short screening scales to monitor population prevalences and trends in non-specific psychological distress. Psychol Med. 2002;32:959-76.

28. Sakurai K, Nishi A, Kondo K, Yanagida K, Kawakami N. Screening performance of $K 6 / K 10$ and other screening instruments for mood and anxiety disorders in Japan. Psychiatry Clin Neurosci. 2011;65:434-41.

29. Himichi T, Osanai H, Goto T, Fujita H, Kawamura Y, Davis MH, et al. Development of a Japanese version of the interpersonal reactivity index. Shinrigaku Kenkyu. 2017:88:61-71.

30. Corp IBM. SPSS statistics for windows version 22.0.0. Armonk: IBM Corp; 2013.

31. Hair JF, Black WC, Babin BJ, Anderson RE. Multivariate data analysis. 7th ed. Upper Saddle River: Pearson Prentice Hall; 2010.

32. Gleichgerrcht $E$, Decety J. Empathy in clinical practice: how individual dispositions, gender, and experience moderate empathic concern, burnout, and emotional distress in physicians. PLoS One. 2013;8:e61526. https://doi. org/10.1371/journal.pone.0061526.

33. Decety J, Jackson PL. The functional architecture of human empathy. Behav Cogn Neurosci Rev. 2004;3:71-100. https://doi.org/10.1177/ 1534582304267187.

34. Decety J, Lamm C. Human empathy through the lens of social neuroscience. Sci World J. 2006;6:1146-63. https://doi.org/10.1100/tsw.2006.221.

35. Pross C. Burnout, vicarious traumatization and its prevention. Torture. 2006; 16:1-9.

36. Fox R, Lief H. Training for "detached concern" in medical students. In: Lief HI, Lief VF, Lief NR, editors. The psychological basis of medical practice. New York: Harper \& Row; 1963. p. 12-35.

37. Sodeke-Gregson EA, Holttum S, Billings J. Compassion satisfaction, burnout, and secondary traumatic stress in UK therapists who work with adult trauma clients. Eur J Psychotraumatol. 2013;4. https://doi.org/10.3402/ejpt.v4i0.21869.

38. Derksen F, Bensing J, Lagro-Janssen A. Effectiveness of empathy in general practice: a systematic review. Br J Gen Pract. 2013;63:e76-84.

39. McCarroll JE, Ursano RJ, Fullerton CS, Lundy A. Traumatic stress of a wartime mortuary: anticipation of exposure to mass death. J Nerv Ment Dis. 1993; 181:545-51. https://doi.org/10.1097/00005053-199309000-00003.

40. Fullerton CS, Ursano RJ, Wang L. Acute stress disorder, posttraumatic stress disorder, and depression in disaster or rescue workers. Am J Psychiatry. 2004;161:1370-6.

41. McLay RN, Deal WE, Murphy JA, Center KB, Kolkow TT, Grieger TA. On-therecord screenings versus anonymous surveys in reporting PTSD. Am J Psychiatry. 2008;165:775-6. https://doi.org/10.1176/appi.ajp.2008.07121960.

42. Goto T, Wilson JP. A review of the history of traumatic stress studies in Japan: from traumatic neurosis to PTSD. Trauma Violence Abuse. 2003:4: 195-209 doi: July 1, 2003. https://doi.org/10.1177/1524838003004003001.

Ready to submit your research? Choose BMC and benefit from:

- fast, convenient online submission

- thorough peer review by experienced researchers in your field

- rapid publication on acceptance

- support for research data, including large and complex data types

- gold Open Access which fosters wider collaboration and increased citations

- maximum visibility for your research: over $100 \mathrm{M}$ website views per year

At BMC, research is always in progress.

Learn more biomedcentral.com/submissions 